A.A-UR- $99-419$

Approved for public release; distribution is unlimited.
Title:

Author(s):

Submitted to:
A GENERALIZED INTERFACE MODULE FOR THE COUPLING OF SPATIAL KINETICS AND THERMAL-HYDRAULICS CODES

$$
\text { CONF-981097-- }
$$

Vincent A. Mousseau

\section{MASTER}

9th Int' 1 Topical Meeting on Nuclear Reactor Therma1 Hydraulics (NURETH9)

San Francisco, CA

$10 / 3-8 / 98$

DISTRISUTHON OF THIS DOCUMENT IS UMMHTED
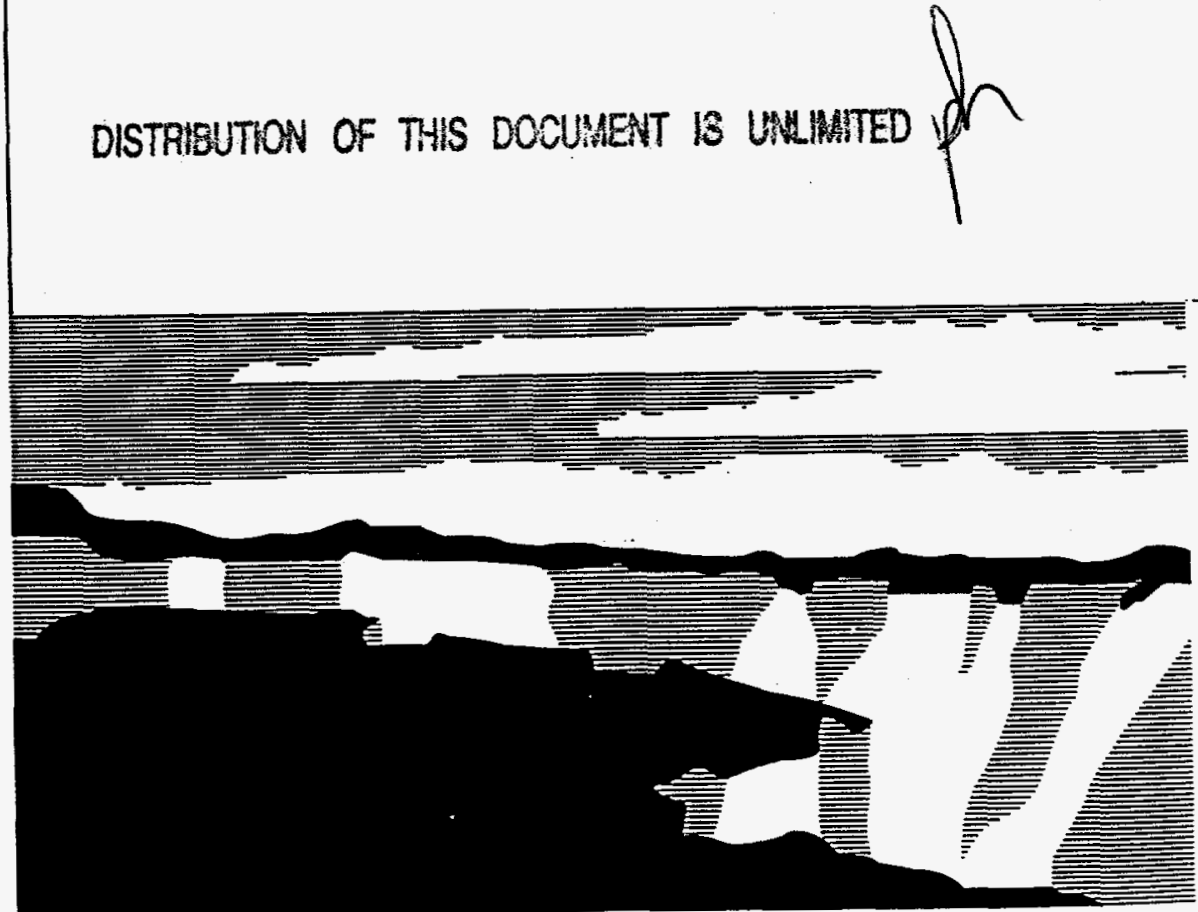

Los Alamos National Laboratory, an affimative action'equal opportunity employer, is operated by the University of California for the

U.S. Department of Energy under contract W-7405-ENG-36. By acceptance of this article, the publisher recognizes that the U.S. Govemment retains a nonexclusive, royalty free license to publish or reproduce the published form of this contribution, or to allow athers to do so, for U.S. Govermment purposes. Los Alamos National Laboratory requests that the publisher Identify this article as work performed under the auspices of the U.S. Department of Energy. The Los Alamos National Laboratory strongly supports academic freedom and a reseancher's right to publish; as an institution, however, the Laboratory does not endorse the viewpoint of a publication or guaranteo its technical correctness. 


\section{DISCLAIMER}

This report was prepared as an account of work sponsored by an agency of the United States Goverament Neitber the United States Government bor any agency thereof, nor any of their employees, makes any warranty, express or implied, or assumes any legal liabiitity or responsibility for the accuracy, compieteners, or usefulness of any information, apparatus, product, or process diselosed, or regresents that its use would not infringe privately owned rights. Reference herein to any speciric commercial producr, process, or service by trade name, tradernark, inanufacturer, or otherwise does not necessarily constitute or imply its endorsement, recommendation, or favoring by the United States Governmeat or any agency thereof. The views and opinions of authors expressed herein do not becessarily state or reflect those of the United States Goveroment or any agency thereof. 


\section{DISCLAIMER}

Portions of this document may be illegible in electronic image products. Images are produced from the best available original document. 
Ninth International Topical Meeting on Nuclear Reactor Thermal Hydraulics (NURETH-9)

San Francisco, California, October 3 - 8, 1999.

\title{
A GENERALIZED INTERFACE MODULE FOR THE COUPLING OF SPATIAL KINETICS AND THERMAL-HYDRAULICS CODES
}

\author{
Douglas A. Barber ${ }^{\text {a }}$, R. Matthew Miller, Han Gyu Joo and Thomas J. Downar \\ Department of Nuclear Engineering \\ Purdue University \\ W. Lafayette, IN 47907-1290 \\ dbarber@scientech.com rmmiller@ecn.purdue.edu \\ joohan@ecn.purdue.edu downar@ecn.purdue.edu \\ Weidong Wang \\ SCIENTECH, Inc. \\ 11140 Rockville Pike, Suite 500 \\ Rockville, MD 20852 \\ wwang@scientech.com \\ Vincent A. Mousseau ${ }^{b}$ and David D. Ebert \\ U.S. Nuclear Regulatory Commission \\ Office of Nuclear Regulatory Research \\ Washington, D.C. 20555-001 \\ vmss@lanl.gov dde@nrc.gov
}

\section{KEY WORDS}

general interface, coupled codes, PVM, thermal-hydraulics, spatial kinetics

\begin{abstract}
A generalized interface module has been developed for the coupling of any thermal-hydraulics code to any spatial kinetics code. The coupling scheme was designed and implemented with emphasis placed on maximizing flexibility while minimizing modifications to the respective codes. In this design, the thermal-hydraulics, general interface, and spatial kinetics codes function independently and utilize the Parallel Virtual Machine software to manage cross-process communication. Using this interface, the USNRC version of the 3D neutron kinetics code, PARCS, has been coupled to the USNRC system analysis codes RELAP5 and TRAC-M. RELAP5/PARCS assessment results are presented for two NEACRP rod ejection benchmark problems and an NEA/OECD main steam line break benchmark problem. The assessment of TRAC-M/PARCS has only recently been initi-
\end{abstract}

a. Present Address - SCIENTECH, Inc.

b. Present Address - Los Alamos National Laboratory 
ated, nonetheless, the capabilities of the coupled code are presented for a typical PWR system/core model.

\section{INTRODUCTION}

Recent advances in cost-effective workstations have made possible the ability of best-estimate thermal-hydraulics codes to provide a three-dimensional neutronic solution capability. From the perspective of the USNRC, this capability is necessary in order to provide accurate audits of licensee safety analysis submittals where 3-D neutronic and thermal-hydraulic effects are important. Thus, in an effort to more easily assess various combinations of 3-D neutronic/thermal-hydraulic codes, the USNRC has sponsored the development of a generalized interface module. This General Interface should provide for the coupling of any thermal-hydraulics code to any spatial kinetics code.

The General Interface manages the mapping of solution variables between thermal-hydraulic and spatial kinetic problem domains, as well as the communication of control logic between the two codes. In order to maintain the applicability of this interface to any thermal-hydraulics or spatial kinetics codes, it is necessary to utilize customized mapping routines which are specific to the codes being coupled. These code-specific data map routines function as secondary interfaces and perform two basic tasks: (1) process the initial and time-dependent control information needed for calculational coherency between the two codes, and (2) control both the processing and the transfer of the vectors of space-dependent solution data both to and from the General Interface.

The initial application of the General Interface is to the best-estimate system thermal-hydraulics code RELAP5 and the USNRC version of PARCS, an advanced reactor core simulator developed at Purdue University (Joo, 1998). In this design, RELAP5, the General Interface, and PARCS are executed as separate processes and communicate with each other through the use of message-passing protocols in the Parallel Virtual Machine (PVM) package (Geist, 1994). The applicability of the General Interface was further tested by the successful coupling of the USNRC's developmental system thermal-hydraulics code, TRAC-M, and PARCS. A detailed description of both the RELAP5/PARCS coupling and the TRAC-M/PARCS coupling is presented in Section 3.

For the assessment of RELAP5/PARCS, the results of two NEACRP rod ejection benchmark problems, one at Hot Zero Power (HZP) and one at Hot Full Power (HFP), will be presented. In addition, a PWR Main Steam Line Break benchmark problem, which has recently been developed at Pennsylvania State University through cooperation with the NEA/OECD, will be used to further assess the 3-D neutronics/thermal-hydraulics capability of RELAP5/PARCS.

Currently, the assessment of TRAC-M/PARCS has been less extensive. However, a simplified Westinghouse 4-Loop model coupled to a typical PWR core neutronic model, will be used to demonstrate the steady-state initialization and critical boron search capabilities of TRAC-M/PARCS. Using this steady-state condition, a Loss of Coolant Acci- 
dent (LOCA) scenario will be run to demonstrate the transient capability of TRAC-M/PARCS.

\section{DESIGN OF GENERAL INTERFACE}

The General Interface is designed as a self-contained process which communicates with the thermal-hydraulic and neutronic processes using the PVM package. In order to facilitate this design, customized routines are utilized which handle the communication between the General Interface and the thermal-hydraulic/neutronic processes. This both minimizes and localizes the changes necessary to the thermal-hydraulics and spatial kinetics codes, and provides a focusing of expertise in that the code developer is not required to have an intimate knowledge of both the thermal-hydraulics and the spatial kinetics codes. In addition, this concept allows independent input processing for the thermal-hydraulic and neutronic codes, which ensures that modifications to existing input decks will be minimal. Fig. 1 depicts the implementation of the General Interlace in the framework of the coupled code.

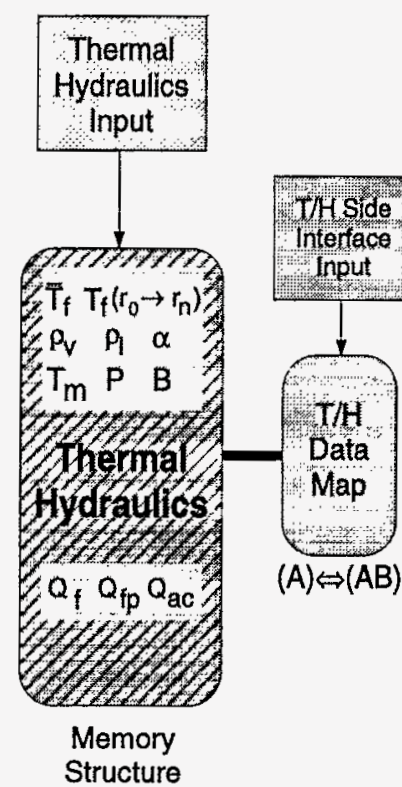

(A)

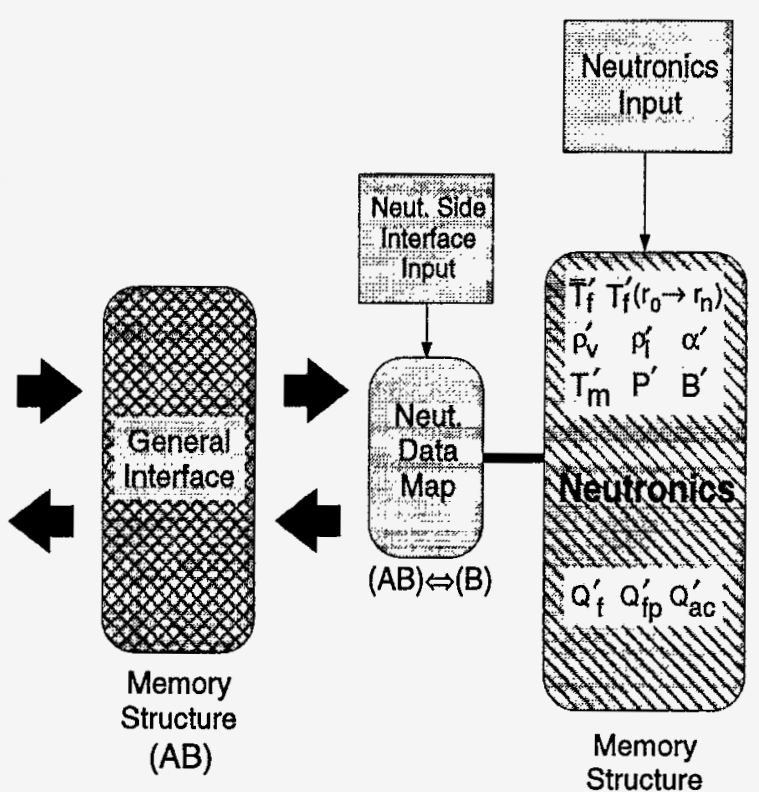

(B)

Fig. 1 Diagram of Interface Implementation.

\subsection{Module Structure and Calculation Control}

The General Interface contains three functional units which correspond to (1) initialization, (2) thermal-hydraulics to neutronics mapping, and (3) neutronics to thermal-hydraulics mapping, as illustrated in Fig. 2. The data which is transferred through the General Interface relates to thermal-hydraulic and neutronic control information (e.g. time step logic, control rod logic, etc.) and thermal-hydraulic and neutronic solution data. The 
mapping between the thermal-hydraulic and neutronic spatial domains is represented by permutation matrices, which are constructed by either of the code-specific routines and sent to the General Interface during the initialization. For the unit controlling the mapping of thermal-hydraulic fluid and conduction data to neutronic nodes, a vector of thermal-hydraulic volume and heat structure variables is passed to the General Interface. Conversely, for the unit controlling the mapping of neutronic data to heat structure components and thermal-hydraulic volumes, a vector containing the neutronic nodal powers is passed to the General Interface.

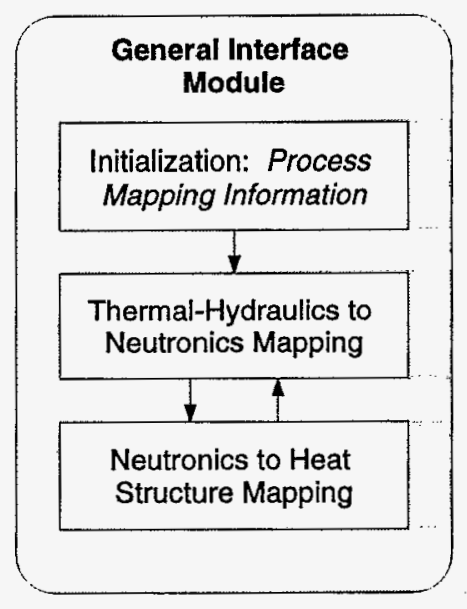

Fig. 2 Structure of the General Interface Module.

In the calculational procedure, the thermal-hydraulic and neutronic modules independently perform input processing, which also includes calls to the code-specific data mapping routines to process the input required by the General Interface (e.g. the permutation matrices). Once the permutation matrices have been processed in either of the code-specific data mapping routines, these matrices are passed to the initialization unit of the General Interface routine to be stored for future use. Following the input processing, the neutronics code calculates the initial power distribution based on the initial thermal-hydraulic condition of the core. Using this power distribution, either the steady-state initialization or the transient calculation can be performed.

Once the input has been processed and each module has been initialized, the flow through the interface routines is the same regardless of whether a steady-state or transient calculation is being performed. Following the advancement of the heat conduction and hydrodynamic calculation, the volume-wise and component-wise variables stored in the thermal-hydraulic memory structure, denoted by $(A)$ in Fig. 1, are packed into a single vector in the T/H Data Map routine (THDMR), converted to the units utilized by the interface, and sent to the General Interface module to be unpacked and stored in the memory structure denoted by $(A B)$. Once this data has been received, the General Interface module performs all data mapping from both thermal-hydraulic volumes and heat structure components to neutronic nodes. The vector of thermal-hydraulic data corresponding to 
neutronic nodes is then sent to the Neutronics Data Map routine (NDMR), where it is unpacked and stored in the neutronics memory structure, denoted by $(B)$. At this point, all necessary unit conversion needed for consistency in the neutronics module is performed.

Upon the completion of the neutronics calculation, the neutronic powers are packed into a single vector by the NDMR, and all necessary unit conversion and/or normalization is performed. This vector of nodal neutronic data is then sent to the General Interface, where it is mapped to thermal-hydraulic volumes and heat structure components. The resulting vector of neutronic powers corresponding to volumes and components is sent to the THDMR, where it is unpacked and stored in the thermal-hydraulic memory structure. Any necessary normalizations or conversions are performed at this point. Fig. 3 illustrates the flow of data between the two codes.

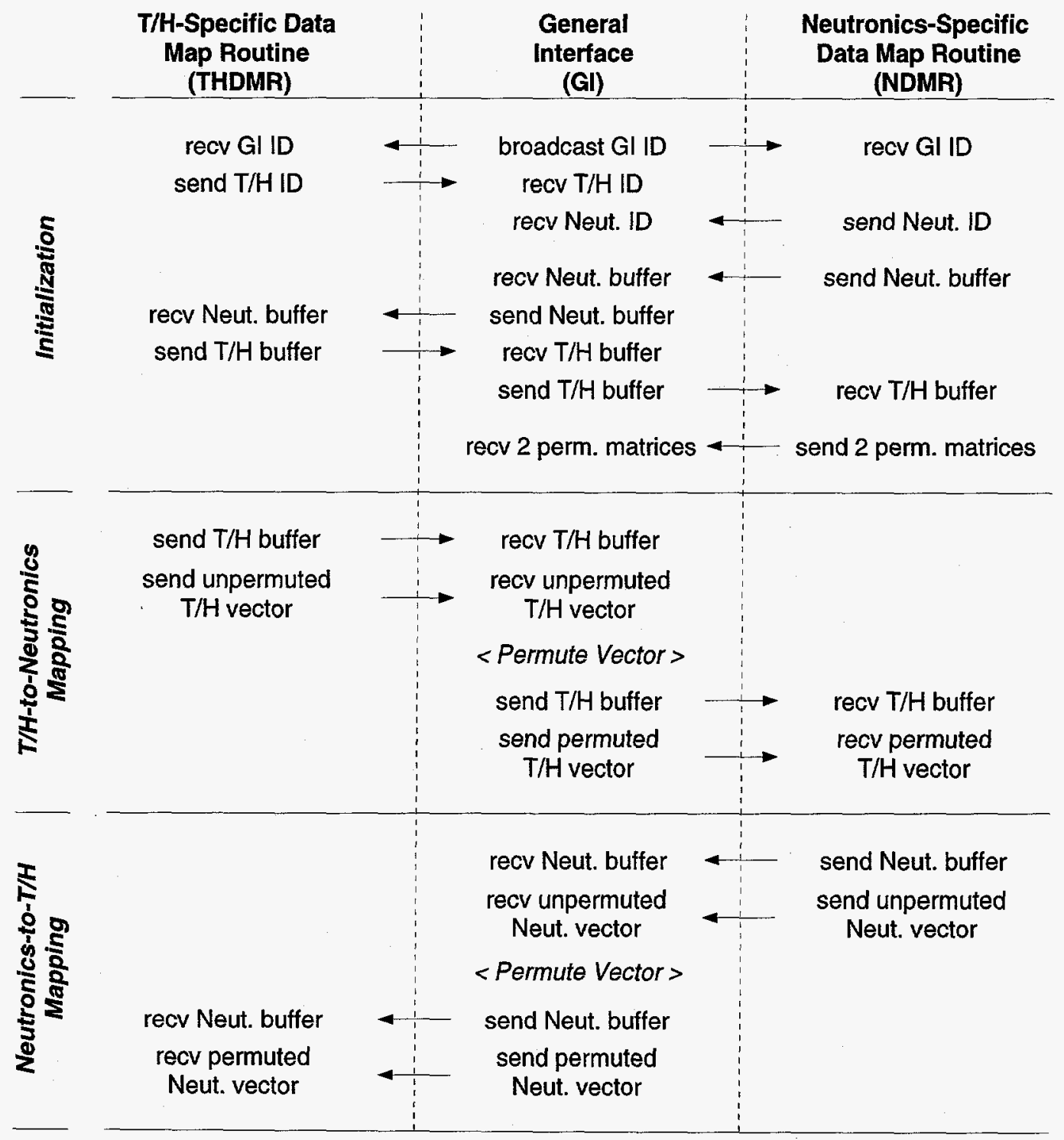

Fig. 3 Demonstration of Communication Flow Between $\mathrm{T} / \mathrm{H}$ and Neutronics Processes. 


\subsection{Mapping Scheme}

The function used by the General Interface to map volume and heat structure data to neutronic nodes is represented as a single permutation matrix, $\boldsymbol{P}$, composed of variable-dependent submatrices of either size $\boldsymbol{n}$-by- $\boldsymbol{m}$ or size $\boldsymbol{n}$-by- $\boldsymbol{m}$ ', where $\boldsymbol{n}$ is the number of neutronic nodes, $\boldsymbol{m}$ is the number of thermal-hydraulic volumes, and $\boldsymbol{m}^{\prime}$ is the number of heat structure components. In practice, a different submatrix is employed for each of the variables passed from the thermal-hydraulics code to allow for separate averaging techniques. The submatrices for the fuel temperatures, which correspond to heat structure components, have dimension $\boldsymbol{n}$-by-m', and the submatrices for the volume-wise thermal-hydraulic property data have dimension $\boldsymbol{n}$-by- $\boldsymbol{m}$. The function used to map neutronic nodal powers to both heat structure components and thermal-hydraulic volumes is represented as a single permutation matrix, $\boldsymbol{P}^{\prime}$. This permutation matrix is composed of submatrices of size $\boldsymbol{m}^{\prime}$-by- $\boldsymbol{n}$ for mapping powers to heat structures, and submatrices of size $\boldsymbol{m}$-by- $\boldsymbol{n}$, which are used to map powers directly to the thermal-hydraulic volumes, in order to account for direct gamma heating to the coolant.

The use of the permutation matrix, $\boldsymbol{P}$, in mapping volume and heat structure data to neutronic nodes is given by:

$$
P x^{H S+\text { Vol. }}=x^{\text {Neut. }} ; x^{H S+\text { Vol. }} \in \mathfrak{R}^{i m^{\prime}+j m} ; x^{\text {Neut. }} \in \mathfrak{R}^{(i+j) n} \text {, }
$$

where the dimension of the vector, $x^{H S+V o l}$, is based on $\boldsymbol{i}$ heat structure variables and $\boldsymbol{j}$ volume variables, and the dimension of $x^{\text {Neut. }}$ is based on $i+j$ total variables. Conversely, the use of the permutation matrix, $\boldsymbol{P}^{\prime}$, in mapping neutronic nodal powers to corresponding heat structure components and thermal-hydraulic volumes is given by:

$$
P^{\prime} x^{\text {Neut. }}=x^{H S+V o l .} ; x^{H S+V o l .} \in \Re^{i m^{\prime}+j m} ; x^{\text {Neut. }} \in \mathfrak{R}^{(i+j) n} \text {, }
$$

where $x^{H S+V o l}$ consists of $i$ powers for the heat structures, and $j$ powers for the fractional deposition in thermal-hydraulic volumes.

The general form of the permutation matrix is given as:

$$
P_{i}=\underset{k(i) \in j}{w_{k(i)}^{i}} e_{k(i)} ; e_{k(i)} \in \Re^{(1, j)} ; \text { for } i=1 \ldots n
$$

where $\boldsymbol{k}(\boldsymbol{i})$ designates the thermal-hydraulic volume(s) belonging to neutronic node $\boldsymbol{i}$, and $\boldsymbol{e}_{\boldsymbol{k}(i)}$ is a row vector with 1 in the $\boldsymbol{k}(\boldsymbol{i})$-th position, and zeros everywhere else. The dimension, $\boldsymbol{j}$, corresponds to either $\boldsymbol{m}$ or $\boldsymbol{m}^{\prime}$, depending on whether the submatrix relates to vol- 
umes or heat structures, respectively. The weighting factor, $w_{k(i)}^{i}$, is a scalar which represents the weighting of the $k(i)$-th volume (or heat structure component) on the $i$-th neutronic node. The restriction on the weighting factor, is given as

$$
\underset{k(i) \in j}{w_{k(i)}^{i}=1.0} \text {. }
$$

It should be noted that for $\boldsymbol{P}$, Eq. (4) represents the summation of elements in row $\boldsymbol{i}$, and for $\boldsymbol{P}^{\prime}$, Eq. (4) represents the summation of elements in column $\boldsymbol{i}$.

An example is shown in Fig. 4, where a planar mapping from cylindrical thermal-hydraulic coordinates to cartesian neutronic coordinates is required.

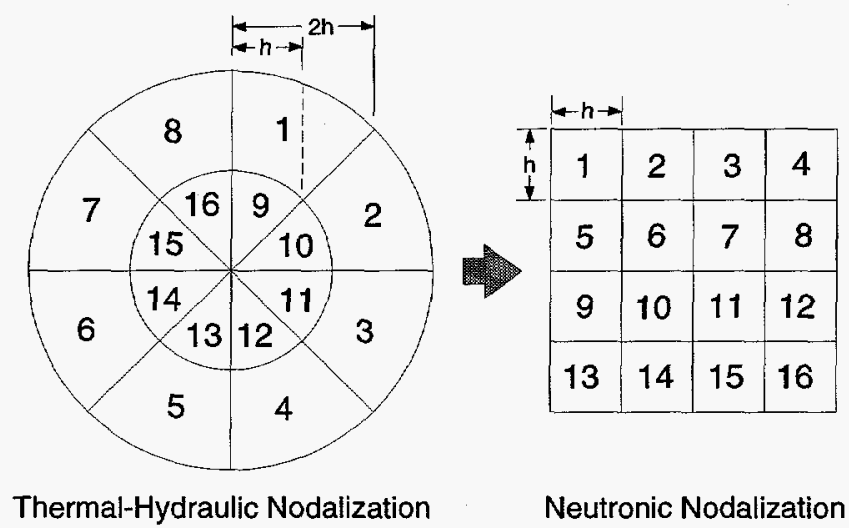

Fig. 4 2-D Mapping Example: Cylindrical to Cartesian

By taking the weighting factors for this example to be simple area fractions, the permutation submatrix for a single thermal-hydraulic variable would be of the form:

$$
\boldsymbol{P}=\left[\begin{array}{cccccccccccccccc}
0 & 0 & 0 & 0 & 0 & 0 & 0.5 & 0.5 & 0 & 0 & 0 & 0 & 0 & 0 & 0 & 0 \\
0 & 0 & 0 & 0 & 0 & 0 & 0 & 0.71 & 0 & 0 & 0 & 0 & 0 & 0 & 0 & 0.29 \\
0.71 & 0 & 0 & 0 & 0 & 0 & 0 & 0 & 0.29 & 0 & 0 & 0 & 0 & 0 & 0 & 0 \\
0.5 & 0.5 & 0 & 0 & 0 & 0 & 0 & 0 & 0 & 0 & 0 & 0 & 0 & 0 & 0 & 0 \\
0 & 0 & 0 & 0 & 0 & 0 & 0.71 & 0 & 0 & 0 & 0 & 0 & 0 & 0 & 0.29 & 0 \\
0 & 0 & 0 & 0 & 0 & 0 & 0 & 0 & 0 & 0 & 0 & 0 & 0 & 0 & 0.5 & 0.5 \\
0 & 0 & 0 & 0 & 0 & 0 & 0 & 0 & 0.5 & 0.5 & 0 & 0 & 0 & 0 & 0 & 0 \\
0 & 0.71 & 0 & 0 & 0 & 0 & 0 & 0 & 0 & 0.29 & 0 & 0 & 0 & 0 & 0 & 0 \\
0 & 0 & 0 & 0 & 0 & 0.71 & 0 & 0 & 0 & 0 & 0 & 0 & 0 & 0.29 & 0 & 0 \\
0 & 0 & 0 & 0 & 0 & 0 & 0 & 0 & 0 & 0 & 0 & 0 & 0.5 & 0.5 & 0 & 0 \\
0 & 0 & 0 & 0 & 0 & 0 & 0 & 0 & 0 & 0 & 0.5 & 0.5 & 0 & 0 & 0 & 0 \\
0 & 0 & 0.71 & 0 & 0 & 0 & 0 & 0 & 0 & 0 & 0.29 & 0 & 0 & 0 & 0 & 0 \\
0 & 0 & 0 & 0 & 0.5 & 0.5 & 0 & 0 & 0 & 0 & 0 & 0 & 0 & 0 & 0 & 0 \\
0 & 0 & 0 & 0 & 0.71 & 0 & 0 & 0 & 0 & 0 & 0 & 0 & 0.29 & 0 & 0 & 0 \\
0 & 0 & 0 & 0.71 & 0 & 0 & 0 & 0 & 0 & 0 & 0 & 0.29 & 0 & 0 & 0 & 0 \\
0 & 0 & 0.5 & 0.5 & 0 & 0 & 0 & 0 & 0 & 0 & 0 & 0 & 0 & 0 & 0 & 0
\end{array}\right] .
$$




\section{APPLICATION OF GENERAL INTERFACE}

The first application of this generalized interface module was to the NRC codes RELAP5 MOD3.2.2Beta and PARCS v1.00, a two-group spatial kinetics code developed at Purdue University (Joo, 1998). This application was then extended to the coupling of TRAC-M and PARCS. TRAC-M is the current developmental version of the NRC consolidated systems thermal-hydraulics code. The coupling schemes used for RELAP5/PARCS and TRAC-M/PARCS are essentially the same with minor differences. Specifically, both use an internal integration scheme for the spatial coupling, and the temporal coupling is treated explicitly. One key difference between the two coupled codes is the solution sequence for the field equations, which will be discussed in the following sections.

\subsection{Coupling of RELAP5 and PARCS}

The spatial coupling of RELAP5 and PARCS relies on an internal integration scheme in which the solution of both the system and core thermal-hydraulics is performed by RELAP5, and PARCS only performs the spatial kinetics solution. The boundary information to be communicated in this scheme is discussed below. The temporal coupling of RELAP5 and PARCS is explicit in nature, and the respective field equations of the two codes are solved with the same frequency. In the implementation discussed here, the RELAP5 solution lags the PARCS solution by one time step.

In the framework of the coupled thermal-hydraulic/neutronic code, RELAP5 and PARCS are designed to be self-contained processes, which communicate with the General Interface process through the use of the constructs supplied with the Parallel Virtual Machine (PVM) package. In order to accommodate the requirements of the General Interface and minimize the coding modifications to both RELAP5 and PARCS, separate code-specific data map routines are needed to manage the transfer of data between these two processes and the General Interface. The RELAP5-specific data map routine (RDMR) manages to basic tasks: (1) the transfer of initial and time-dependent control information needed for calculational coherency between PARCS and RELAP5, and (2) the processing and the transfer of the vectors of space-dependent solution data both to and from the General Interface at each time step. The PARCS-specific data map routine (PDMR) manages a third task, in addition to the two mentioned above, which relates to the processing and the transfer of the permutation matrices to the General Interface.

The permutation matrices constructed by the PDMR consist of a block structure, where each block submatrix corresponds to a particular solution variable (e.g. subvector) to be permuted. The data to be mapped from RELAP5 to PARCS consist of the following thermal hydraulic subvectors (in order): moderator temperature $\left(T_{m}\right)$, liquid density $\left(\rho_{l}\right)$, vapor density $\left(\rho_{v}\right)$, void fraction $(\alpha)$, and boron concentration $(B)$. These subvectors are then followed by the heat structure subvectors (in order): average fuel tempera- 
ture $\left(T_{f}\right)$, fuel centerline temperature $\left(T_{f}^{0}\right)$, and fuel surface temperature $\left(T_{f}^{\mathcal{S}}\right)$. The data to be mapped from PARCS to RELAP5 relate to the space-dependent powers obtained from the spatial kinetics calculation, and consist of the total power to thermal-hydraulic volumes $\left(Q_{\mathrm{t}}^{\mathrm{T} / \mathrm{H}}\right)$ to account for direct gamma heating to the coolant, and total power to heat structure components $\left(Q_{\mathrm{t}}^{\mathrm{HS}}\right)$. Fig. 5 illustrates the structure of these permutation matrices.

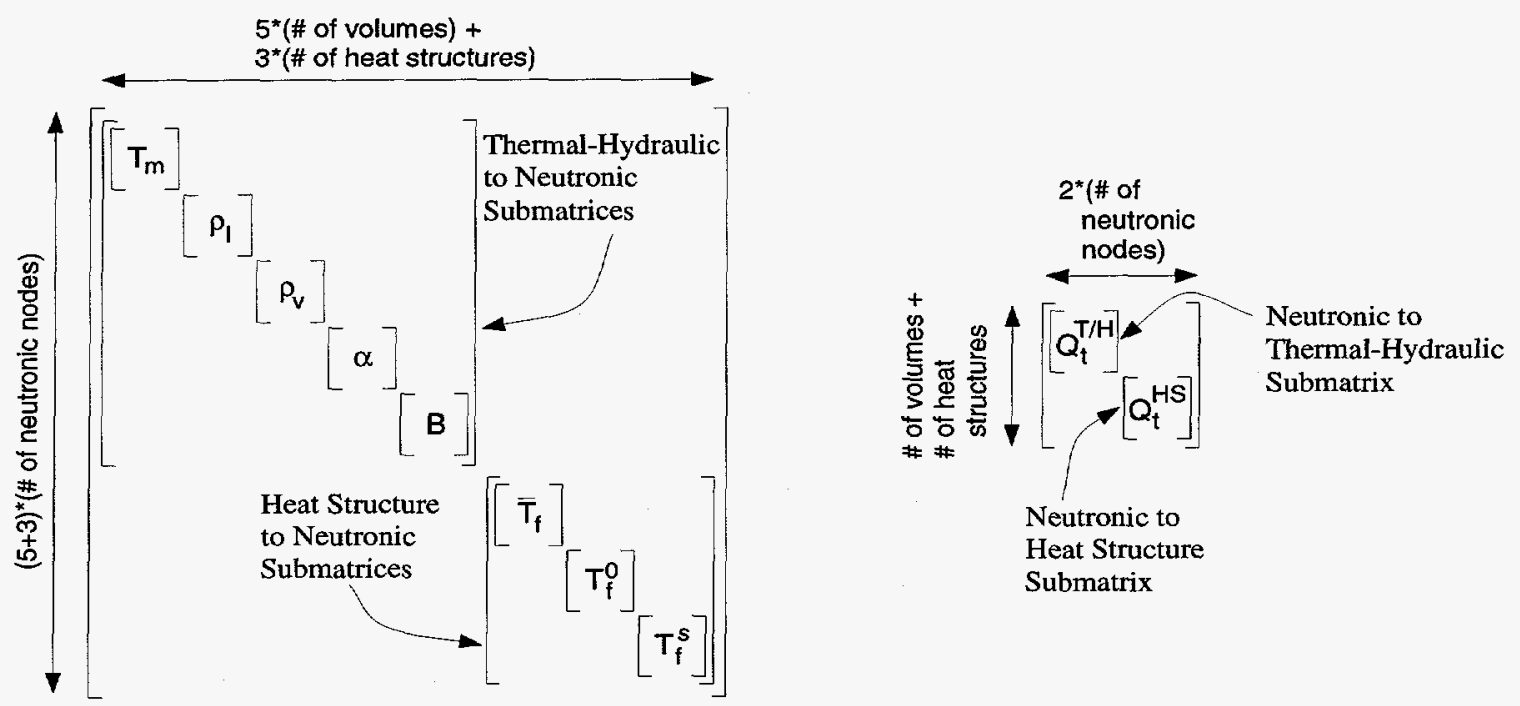

Fig. 5 Structure of the Permutation Matrices.

The process flow for RELAP5/PARCS begins with independent input processing for RELAP5 and PARCS, which is followed by respective calls to the RDMR and PDMR to synchronize the calculation and setup the communication between RELAP5, the General Interface, and PARCS. Once this is complete, the second unit of the RDMR is called to transfer thermal-hydraulic initial condition data to the General Interface. This data is then used by PARCS to incorporate appropriate feedback into the cross sections and construct the linear system to be solved. PARCS then performs an eigenvalue calculation to obtain the core k-effective and initial power shape, and calls the third unit of the PDMR to send the space-dependent neutronic powers to the General Interface. The third unit of the RDMR is called by RELAP5 to receive these powers and map them to the appropriate RELAP5 memory locations.

The time-dependent calculation is initiated by first advancing the heat conduction and hydrodynamic solutions. Following this solution, the second unit of the RDMR is called to process all necessary time- and space-dependent thermal-hydraulic data and send this data to the General Interface. The second unit of the PDMR is called to obtain this data from the General Interface. Once this data has been received and stored in memory, PARCS incorporates the appropriate feedback into the cross sections, constructs the linear 
system, and performs the time-dependent spatial kinetics solution for the time step dictated by RELAP5. PARCS then calls the third unit of the PDMR in order to transfer the time- and space-dependent neutronics power to the General Interface. The third unit of the RDMR receives and stores this data in RELAP5 memory, and returns control to RELAP5, which will perform the thermal-hydraulic calculation if the final time step has not been performed. This procedure, which is depicted in Fig. 6, is repeated until RELAP5 indicates that the calculation should be terminated, or a fault signal is detected. It should be noted that this procedure is the same for steady-state initialization cases.

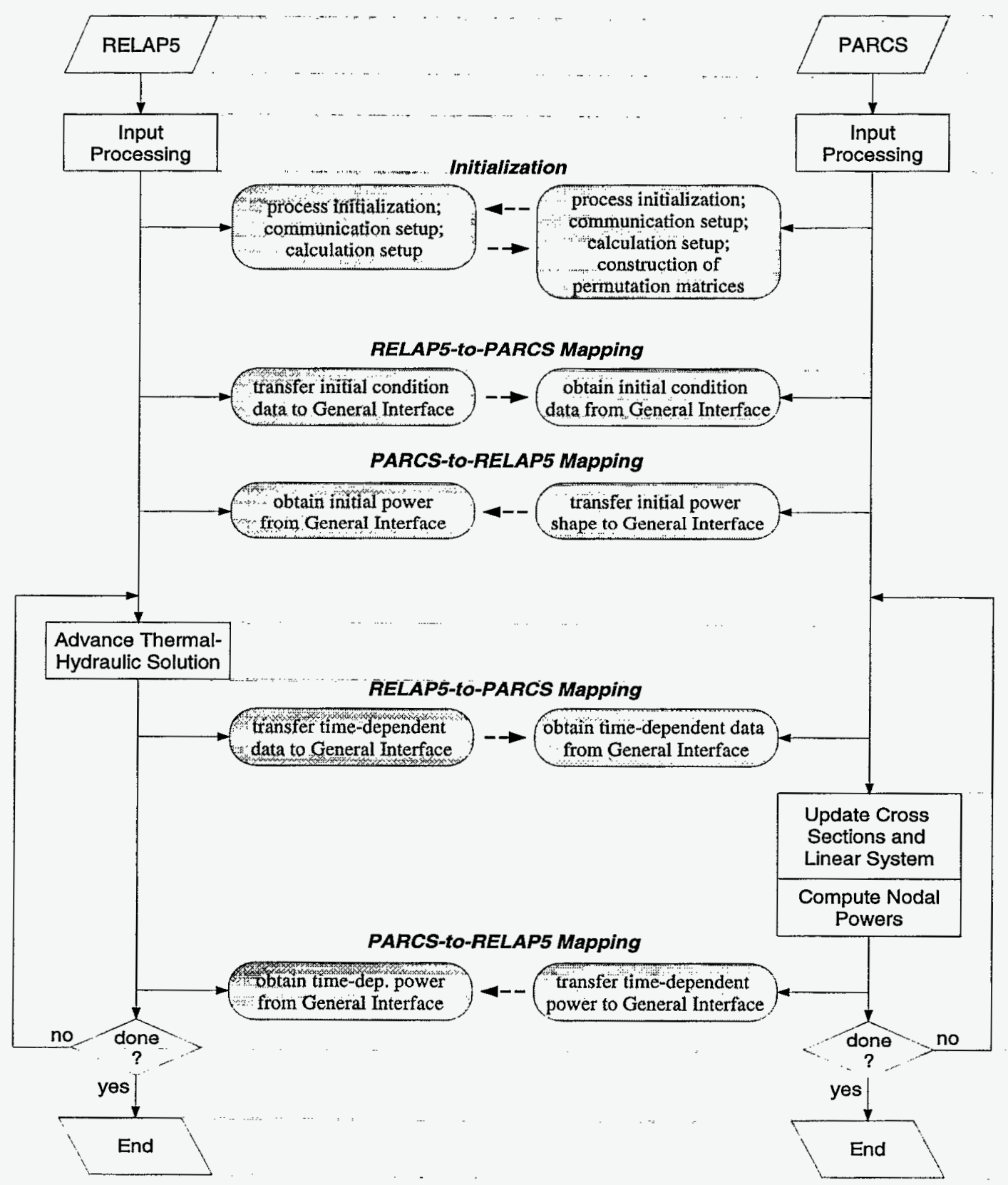

Fig. 6 Process Flow for RELAP5/PARCS 


\subsection{Coupling of TRAC-M and PARCS}

The ability of the General Interface to couple any thermal-hydraulic code to any neutronic code is further demonstrated by the successful implementation within the framework of the TRAC-M/PARCS coupled code. The spatial and temporal coupling of TRAC-M/PARCS is the same as that used for RELAP5/PARCS, however, the order of solving the field equations within TRAC-M differs slightly from that in RELAP5, as will be discussed in the following paragraph. In addition, the TRAC-M-Specific data mapping routine (TDMR) supports all the functionality of the RELAP5/PARCS coupled code while also providing the user with the ability to perform a boron criticality search during steady-state calculations.

In order to increase the numerical stability of the coupled TRAC-M/PARCS code, the physical phenomena with the shortest time constant should be modeled most implicitly. Although the coupling scheme in the TRAC-M/PARCS code is explicit in nature, the order in which the hydrodynamics, heat conduction, and neutronics equations are solved can be modified to enhance numerical stability. In the TRAC-M/PARCS coupled code, the hydrodynamic condition is updated prior to the solution of the heat conduction equations, where the heat source is based on the neutronic nodal powers from the previous time step. Thus, the thermal-hydraulic and heat conduction solutions lag the neutronic solution, which follows the trend of decreasing time constant being treated with increasing implicitness. Fig. 7 depicts the process flow for TRAC-M when coupled to PARCS.

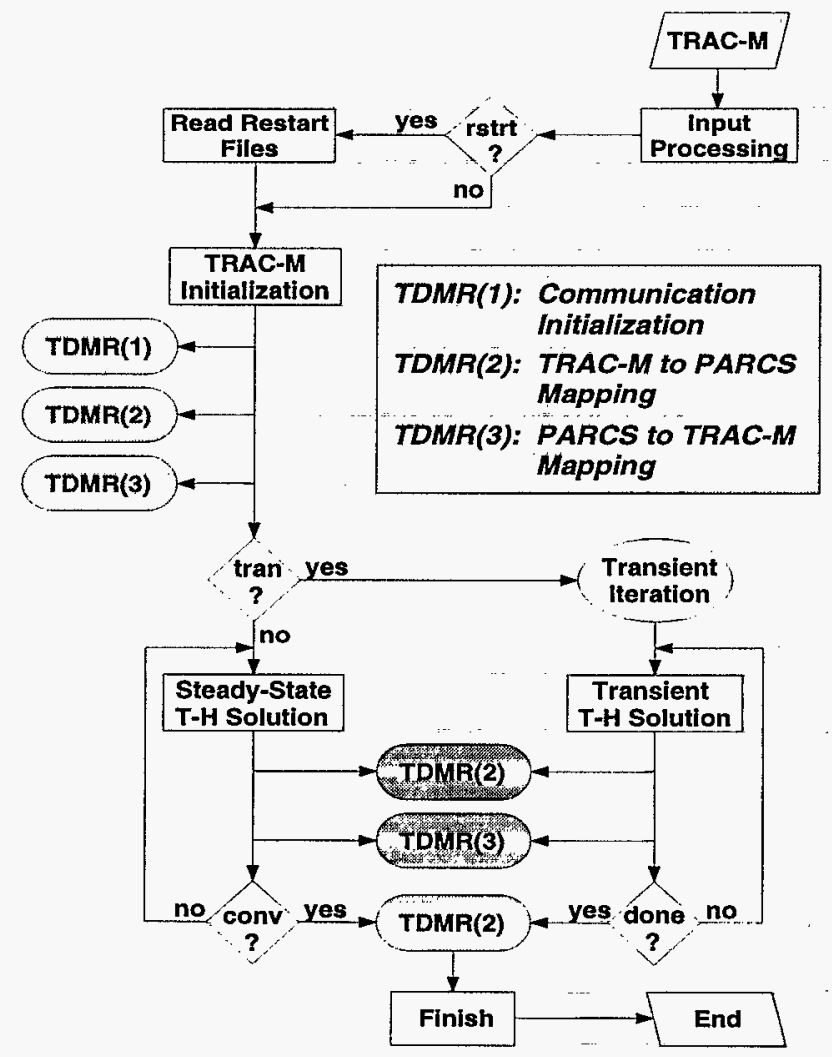

Fig. 7 Process Flow for TRAC-M/TDMR 
As mentioned, the data map routine within TRAC-M supports all the functionality of the RELAP5/PARCS coupled code and provides the user with the ability to perform boron criticality searches within the framework of the TRAC-M/PARCS coupled code. TRAC-M performs all boron transport calculations, while PARCS uses this spatial boron concentration to incorporate feedback into the nodal cross sections. In some steady-state calculations, it is desirable to determine the global boron concentration that gives a core k-effective of unity. Because of the inherent feedback of the boron concentration on $\mathrm{k}$-effective, the determination of the critical boron concentration is performed by PARCS. However, the results of the critical boron concentration should be reflected in the TRAC-M model in order to provide PARCS with thermal-hydraulic conditions consistent with those required for criticality. In order to provide this consistency, PARCS computes a ratio by which the spatial boron concentration within the TRAC-M model should by multiplied in order to match the boron concentration calculated by the criticality search. The data mapping routine within TRAC-M then detects whether a criticality search is being performed and adjusts the boron concentrations accordingly.

\section{COUPLED CODE ASSESSMENT}

This section discusses the current state of assessment for both RELAP5/PARCS and TRAC-M/PARCS. Concerning RELAP5/PARCS, results are presented below for two benchmark problems. Although the functional verification of TRAC-M/PARCS has been successfully performed using a suite of test problems, the assessment has only recently been initiated. Thus, Section 4.2 will present results demonstrating the current capabilities of this coupled code.

\subsection{Assessment of RELAP5/PARCS}

Two benchmark problems have been used for the assessment of the RELAP5/PARCS coupling. The first involves two PWR rod ejection problems from the NEACRP Benchmark Specifications (Finnemann, 1992). These problems are largely kinetic events where Doppler temperature is the dominant reactivity feedback mechanism. The second assessment problem is Exercise 2 of the OECD PWR Main Steam Line Break Benchmark Specifications (Ivanov, 1997). This problem involves a "plenum-to-plenum" core/vessel model where the time-dependent flow boundary conditions are specified. Accurate 3-D neutronic/thermal-hydraulic modeling is required in order to correctly predict the space-time effects arising from the asymmetric cooling of the core, and the resulting scram with an assumed stuck rod. 


\subsubsection{NEACRP Rod Ejection Benchmark}

The first NEACRP problem examined here involves the ejection of a control assembly from the center of an initially critical core at hot zero power (problem A1). The second NEACRP problem uses the same core geometry and data, except the control rod is ejected from an initially critical core at hot full power (problem A2). After the ejection of the control assembly, the coupled neutron flux field, and temperature/fluid field equations are solved for a period of one second. This transient involves a large redistribution of core power and is a severe test of the neutronics and core related thermal/hydraulics capability in a reactor simulation code.

For this problem, the PWR fuel assembly consists of an array of fuel rods and water channels which are homogenized for purposes of both the neutronic and hydrodynamic calculations. Each fuel assembly of the core is modeled as one $\mathrm{T} / \mathrm{H}$ channel with four radial neutronic nodes. Eighteen axial nodes are used for the neutronic model and fourteen axial nodes are used for the $\mathrm{T} / \mathrm{H}$ model, with the three small axial nodes located at both the top and bottom of the core being collapsed into a single node. Fig. 8 illustrates this neutronic and thermal-hydraulic discretization.

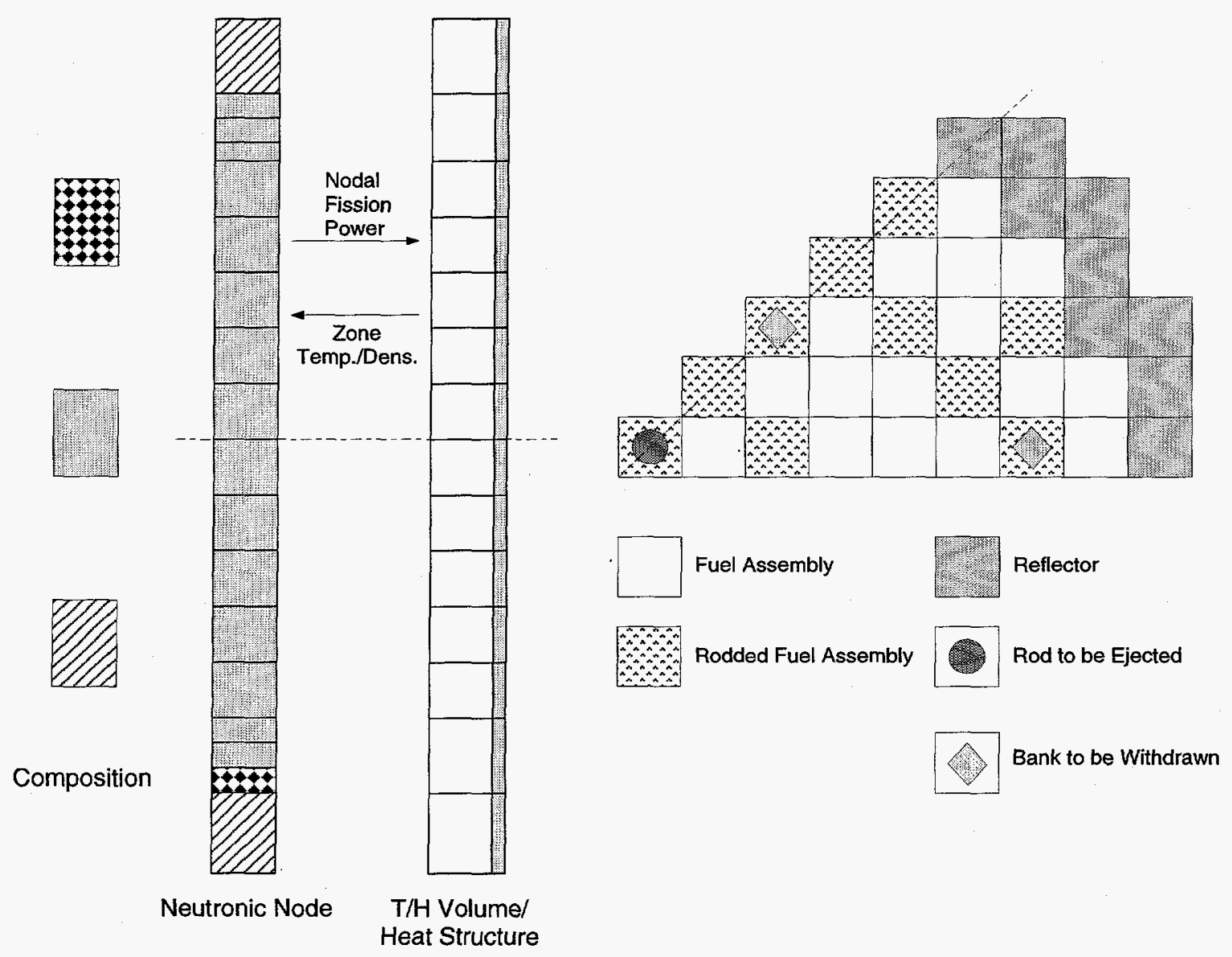

Fig. 8 NEACRP Model: Left - Axial Nodalization; Right - 1/8-Core Neutronic Model. 
The solution was analyzed by comparison with a published reference solution (Knight, 1996) obtained by using a finer spatial and temporal resolution than in standard calculations. The transient core power and doppler temperature response for the NEACRP-A1 problem is shown in Fig. 9, and the transient core power response for the NEACRP-A2 problem is shown in Fig. 10. As indicated in Fig. 9 and Fig. 10, RELAP5/PARCS closely matches the reference solution of PANTHER for both problems.

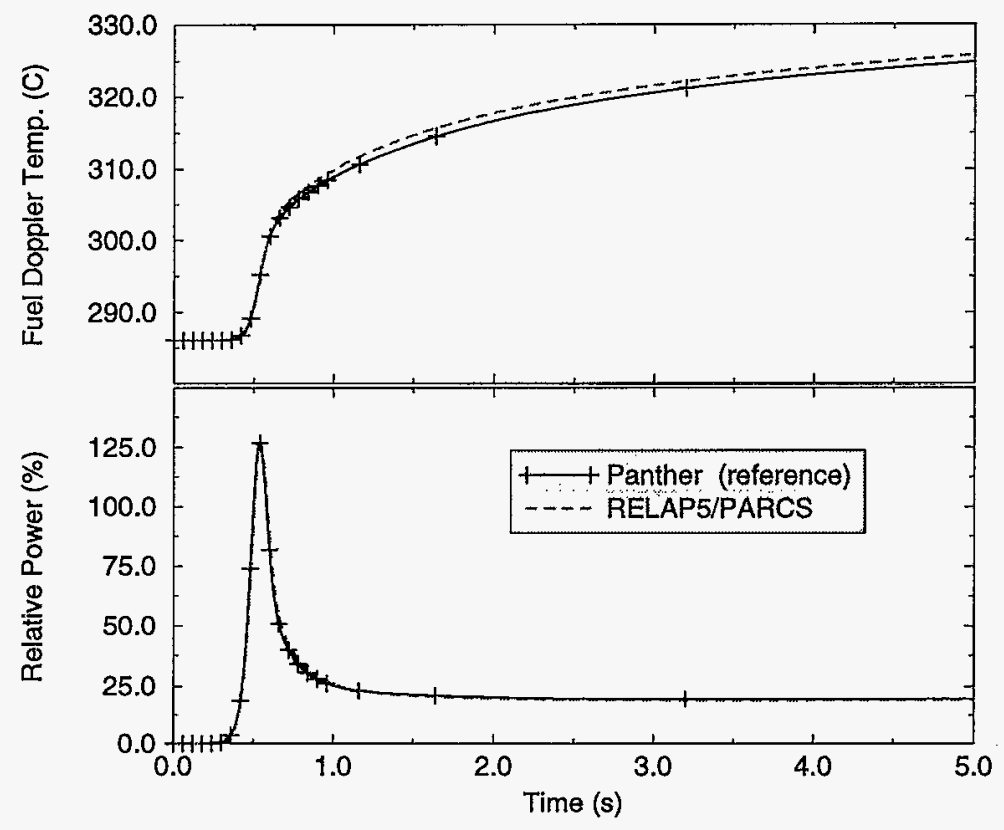

Fig. 9 NEACRP (A1) Core Transient Response

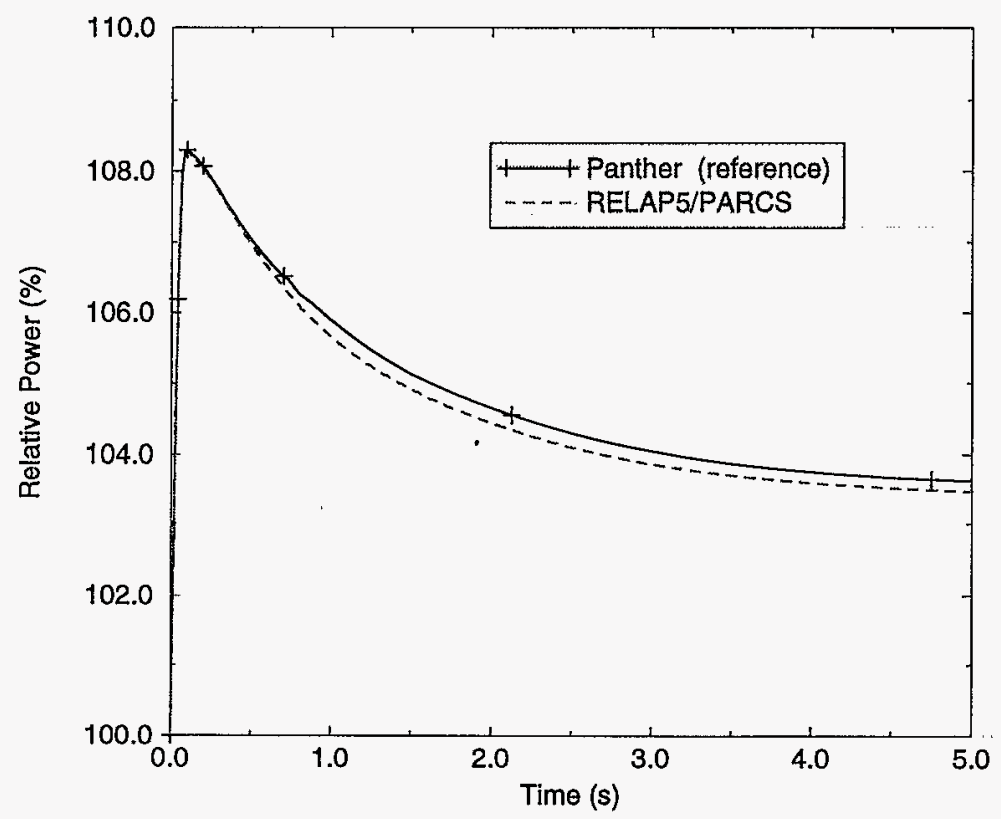

Fig. 10 NEACRP (A2) Core Transient Response. 


\subsubsection{OECD PWR MSLB Benchmark}

The core model used for this benchmark is based on an end of cycle (EOC) state of the TMI-I nuclear power plant. The core consists of 177 fuel assemblies (FA), and the rated power is $2772 \mathrm{MW}$ (th). The radial bypass region is represented by a ring of square nodes whose total area is equal to 64 times the area of a single FA. The active core height is $357.12 \mathrm{~cm}$, and a $21.811 \mathrm{~cm}$ thick reflector region is modeled at the top and bottom of the active core. Further information about this problem can be obtained from Ivanov, et al. (1997) and Beam, et al. (1998).

The PARCS model uses one neutronic node per fuel assembly in the radial direction, and 26 nodes in the axial direction. The RELAP5 model uses 18 independent flow channels which represent 3 radial and 6 azimuthal regions. The inner, middle, and outer regions consist of Channels 1-6, 7-12, and 13-18, respectively. In addition, a separate channel is used for modeling the bypass region. Each flow channel consists of inlet and outlet reservoirs in the form of a time-dependent volume and a pipe. A time-dependent junction is used to connect the inlet reservoir and the pipe, while a single junction is used between the pipe and the outlet reservoir. The flow conditions are specified as a function of time up to 100 seconds and consist of inlet temperature, inlet mass flow rate, inlet pressure, and outlet pressure. The configuration of a single flow channel is depicted in Fig. 11.

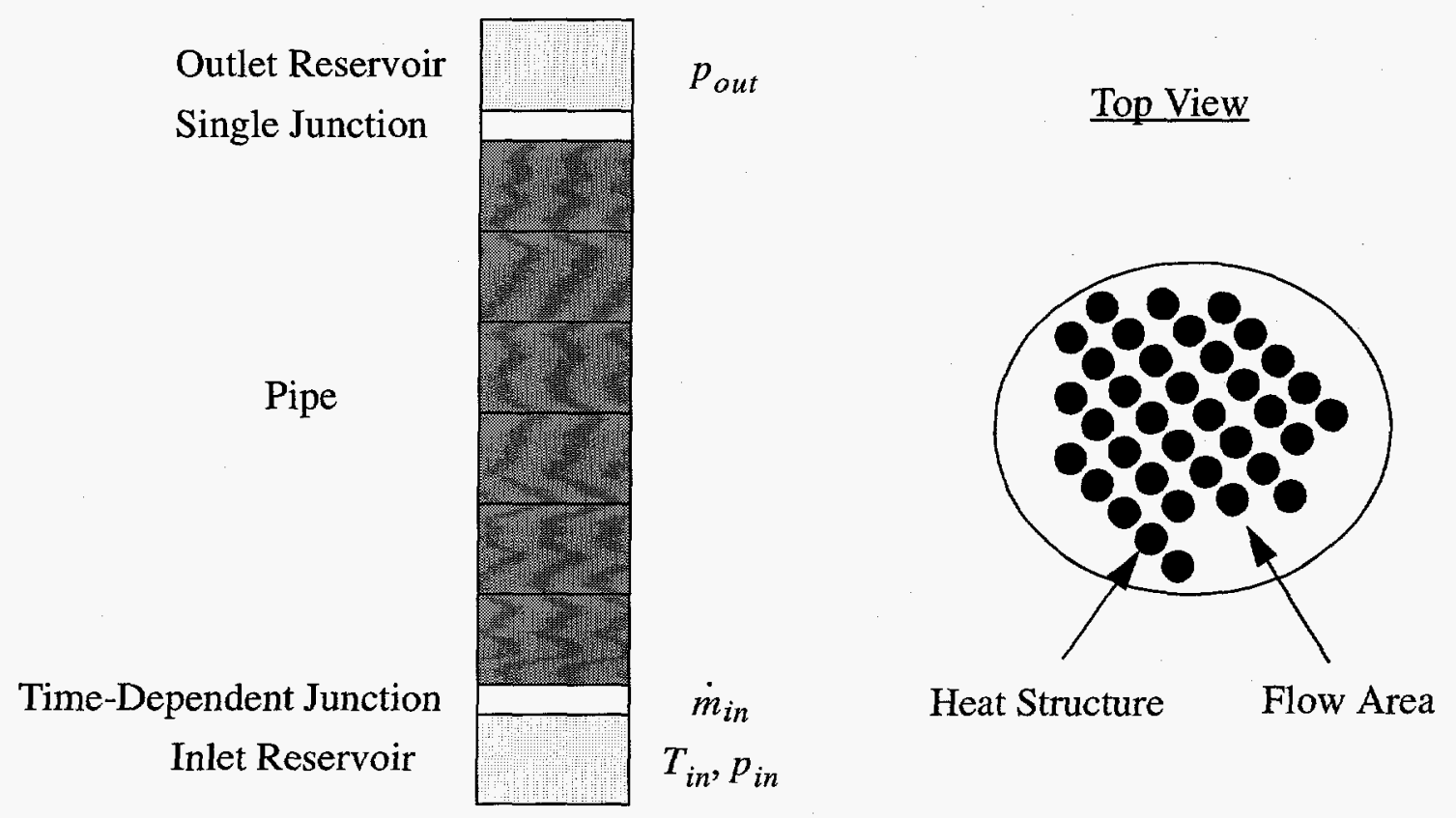

Fig. 11 Flow Channel Configuration

In the RELAP5 model, a heat structure represents each assembly separately. Since there are 177 fuel assemblies in the core, the number of heat structures should be at least 177. In addition, the 15 fuel assemblies located on the $x$-axis need two heat structures 
because each half of the assembly belongs to a different channel. An additional heat structure is also required for the radial reflector. Thus, a total of 193 heat structures are defined.

There are 7 control rod groups in the core, and at the initial steady state condition, all of the control rods, except Group 7, are fully withdrawn. The control rods of Group 7 are $93 \%$ withdrawn, with the exception of the one assumed stuck rod which remains fully withdrawn throughout the steady state and transient calculations.

The steady-state initialization is performed by first running RELAP5 in stand-alone mode (i.e. without PARCS) to establish the fully-developed flow, as well as the asymptotic fuel temperature distribution. This is achieved by running a null transient with constant power starting from a uniform temperature distribution corresponding to HZP. Once the flow condition is converged, RELAP5 and PARCS are run in coupled mode until sufficient convergence is reached in the core k-effective. The key output parameters obtained for the initial HFP state are given in Table 1. In addition, the initial radial power distribution can be seen in the upper-left plot of Fig. 13.

Table 1 Key Output Parameters of the RELAP5/PARCS Calculation for the HFP Initial Steady-State (ANM, 1 Node/FA, 193 HS)

\begin{tabular}{|c|c|c|c|c|c|}
\hline$k_{\text {eff }}$ & $\begin{array}{l}\bar{T}_{\text {out }} \\
(K)\end{array}$ & $\begin{array}{c}\bar{T}_{\text {core }} \\
(K)\end{array}$ & $\begin{array}{c}\bar{d}_{\text {out }} \\
\left(\mathrm{kg} / \mathrm{m}^{3}\right)\end{array}$ & $\begin{array}{c}\bar{d}_{\text {core }} \\
\left(\mathrm{kg} / \mathrm{m}^{3}\right)\end{array}$ & $\begin{array}{c}\bar{T}_{\text {Dore }} \\
(K)\end{array}$ \\
\hline 1.00516 & 592.5 & 580.3 & 682.1 & 710.9 & 824.7 \\
\hline
\end{tabular}

In the transient calculation, RELAP5 and PARCS are both restarted from the end of the initial steady-state, and the time-dependent flow boundary conditions are triggered at time zero. A fixed time step size of $100 \mathrm{~ms}$ is used thought the transient except for the period from 6.0 to $6.1 \mathrm{sec}$ in which the time step size is reduced to 0.01 to match the scram time of $6.02 \mathrm{sec}$.

Fig. 12 shows the time variation of the primary input and output parameters, including the reactivity components which drive the transient. The figure indicates that the density feedback is the dominant positive reactivity insertion mechanism, as is expected. The maximum return-to-power occurs at $60.2 \mathrm{sec}$ with a magnitude of $33.1 \%$. The core, however, does not return to critical and the maximum reactivity of -3.72 cent at $57.5 \mathrm{sec}$ is only slightly subcritical. The reason there is a return to power even though the core remains subcritical has been recently presented by Gose, et al. (1998). Briefly, whether there is a return to power or not is determined by the rates of two competing processes. If the rate of increase in subcritical multiplication (i.e. rate of increase in reactivity) is greater than the rate of decrease in the delayed neutron population, the power level will increase. Rates of change in subcritical multiplication are very sensitive to the rates 
of change in the thermal hydraulic conditions. Therefore, small errors in the calculation of the thermal-hydraulic conditions can cause large changes in the rates of subcritical multiplication.

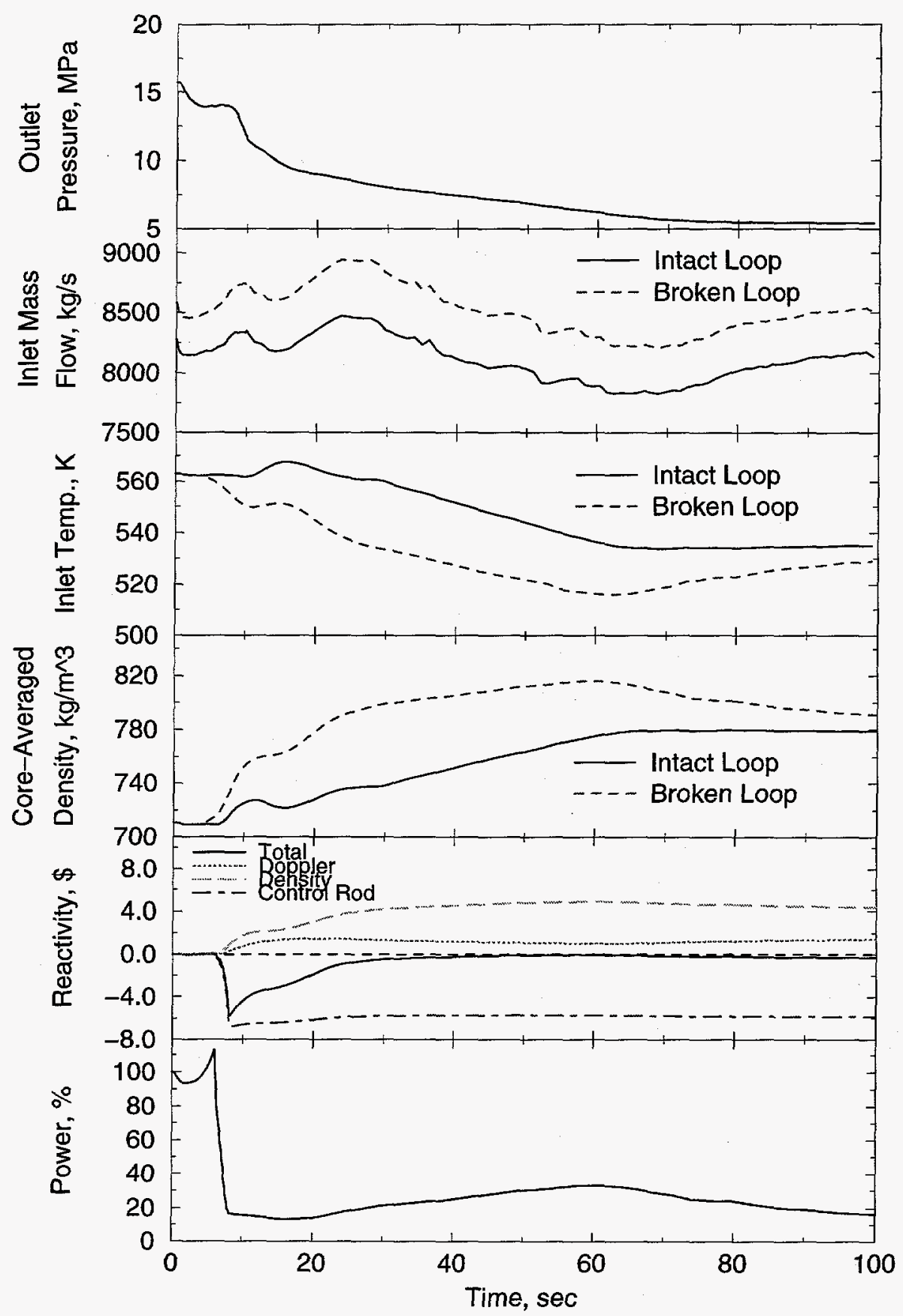

Fig. 12 MSLB Transient Result Summary

Although the magnitude of the return-to-power is only slightly significant, the radial power shape experiences severe changes as shown in Fig. 13. The radial assembly 
power peaking factor, which is 1.33 at the initial state, reaches its maximum of 3.85 at 30 sec, and then diminishes to 3.29 at $100 \mathrm{sec}$.

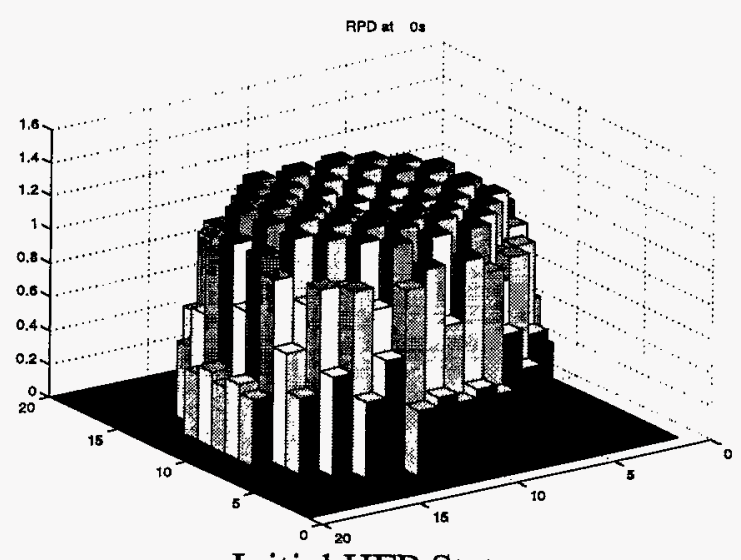

Initial HFP State

RPD at $8=$

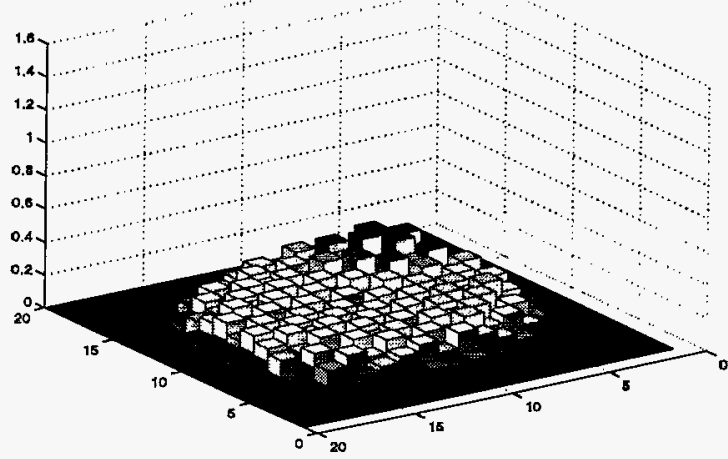

Right after the Scram (@8.3 sec)

RPD at 60 :

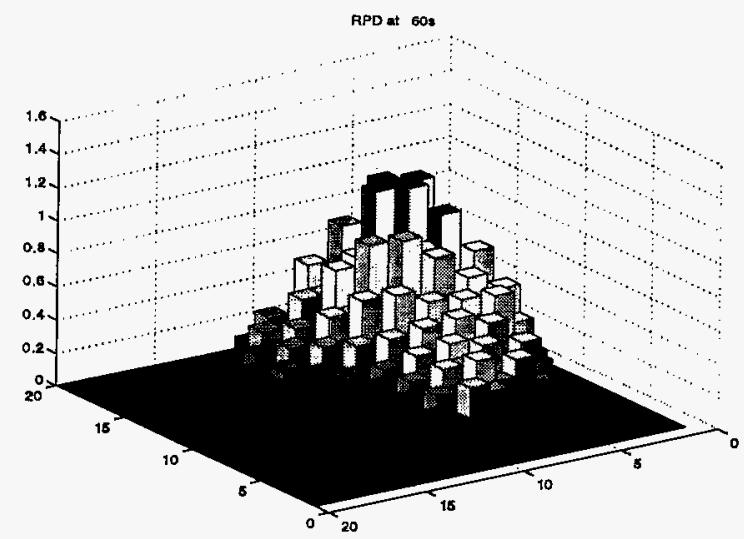

Maximum Return to Power (@60sec)

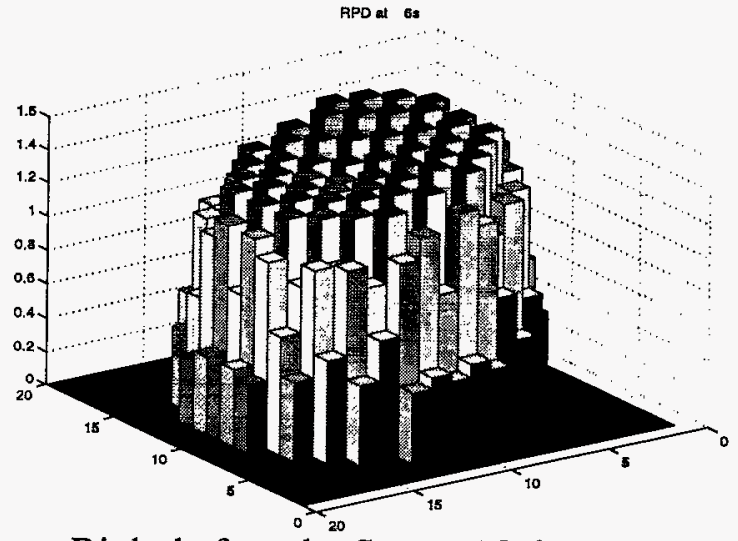

Right before the Scram (@6.02sec)

RPD at 30:

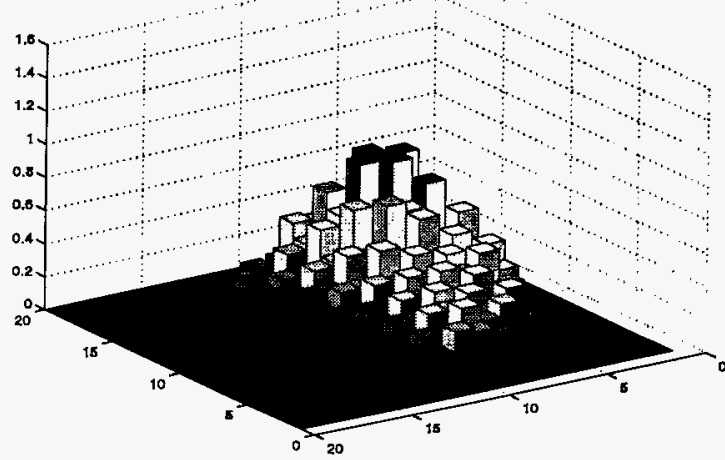

Maximum Ass'y Power Peaking (@30sec)

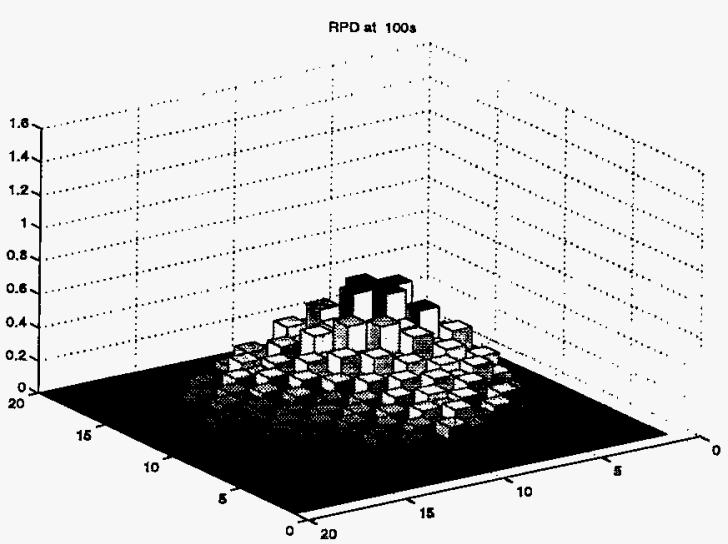

End of the Transient (@100sec)

Fig. 13 Evolution of Radial Power Distribution During MSLB Transient 


\subsection{Preliminary Assessment of TRAC-M/PARCS}

For the demonstration of the capabilities of the TRAC-M/PARCS coupled code, a simplified Westinghouse 4-Loop (W4Loop) PWR model is used for TRAC-M and a typical PWR (TypPWR) core model is used for PARCS, where the cross sections are taken from the NEACRP Benchmark Specifications (Finnemann, 1992). The TRAC-M model consists of 33 thermal-hydraulic components broken into a total of 124 cells and 15 heat structures. The vessel component in this model is divided into 7 axial layers, 2 radial regions, and 4 azimuthal regions, making up 56 total vessel cells. The remaining cells make up the steam generators, pressurizer, and necessary piping. The nominal power for the Westinghouse model is $3250 \mathrm{MW}$, and a single heat structure is used to model 4 average rods, each representing 9,843 fuel rods.

As discussed in Section 3.2, TRAC-M/PARCS has the capability to perform a critical boron concentration (CBC) search during the steady-state initialization. To demonstrate this capability, the W4Loop/TypPWR model was initialized by allowing PARCS to perform a CBC search, and subsequently updating the boron concentration levels in the TRAC-M database. Fig. 14 displays the k-effective and boron concentration results obtained from this steady-state initialization. As can be seen, convergence is not achieved until the core k-effective stabilizes around unity. The boron concentration corresponding to this k-effective of unity is $1459.32 \mathrm{ppm}$.

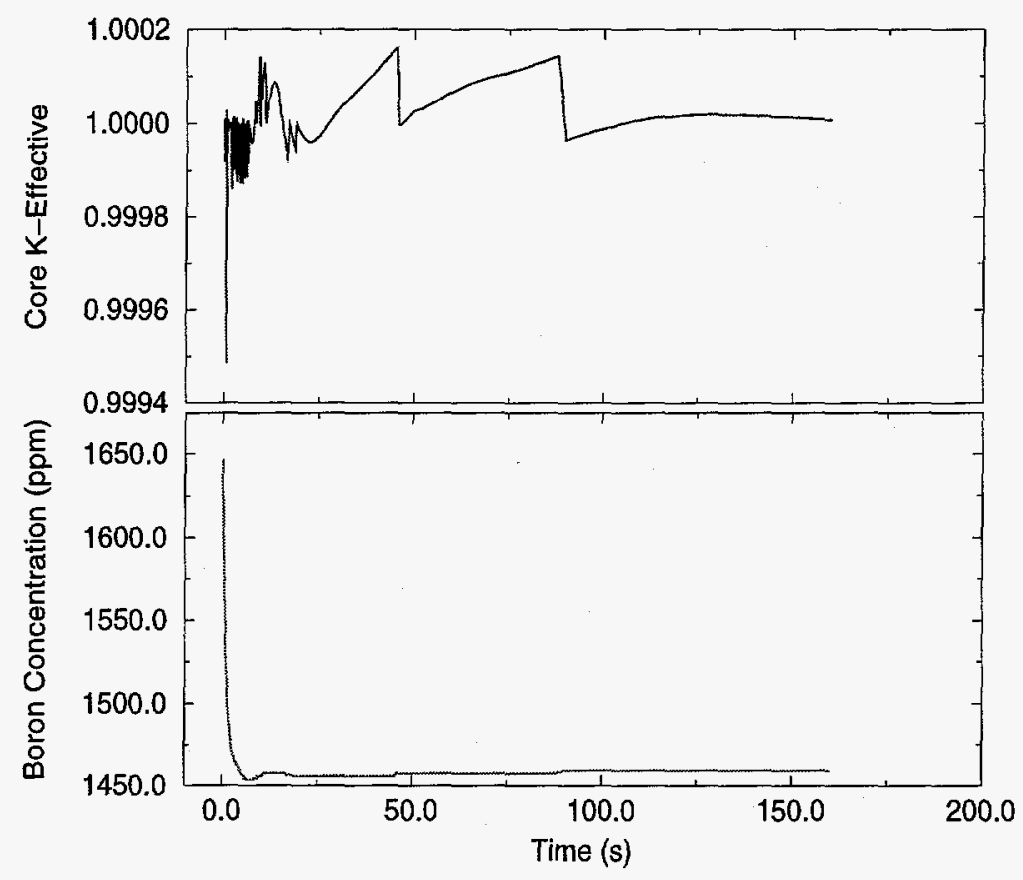

Fig. 14 Steady-State Critical Boron Search with TRAC-M/PARCS

The event used to demonstrate the transient capability of TRAC-M/PARCS is a large break Loss of Coolant Accident (LOCA) through a simulated hot leg break. For this 
event, the three intact hot legs are lumped together, while the broken leg is modeled explicitly. The broken loop is modeled through the opening of a valve in the broken leg over the course of 0.1 seconds. This break causes a depressurization of the primary system, with significant voiding occurring in the vessel. The depressurization and subsequent decrease in moderator density introduces a negative reactivity feedback, causing a sharp drop in reactor power. Control rod scram is set at $1.4 \mathrm{sec}$ and represents the trip due to low pressurizer pressure. The time step size for this problem was dictated by TRAC-M with an allowable range between $1 \mathrm{~ms}$ and $100 \mathrm{~ms}$, and the average time step size was approximately $30 \mathrm{~ms}$.

The transient summary for this event, which was analyzed for a period of $25 \mathrm{sec}-$ onds, is shown in Fig. 15. The depressurization due to the break is evident in the power response shown in the figure. The scram signal which was received at 1.4 seconds caused the control rods to scram in over a period of 2.4 seconds. The oscillation seen in the control rod component of reactivity, and thus the total reactivity, is non-physical and arises from the nodal update scheme used in the PARCS model.

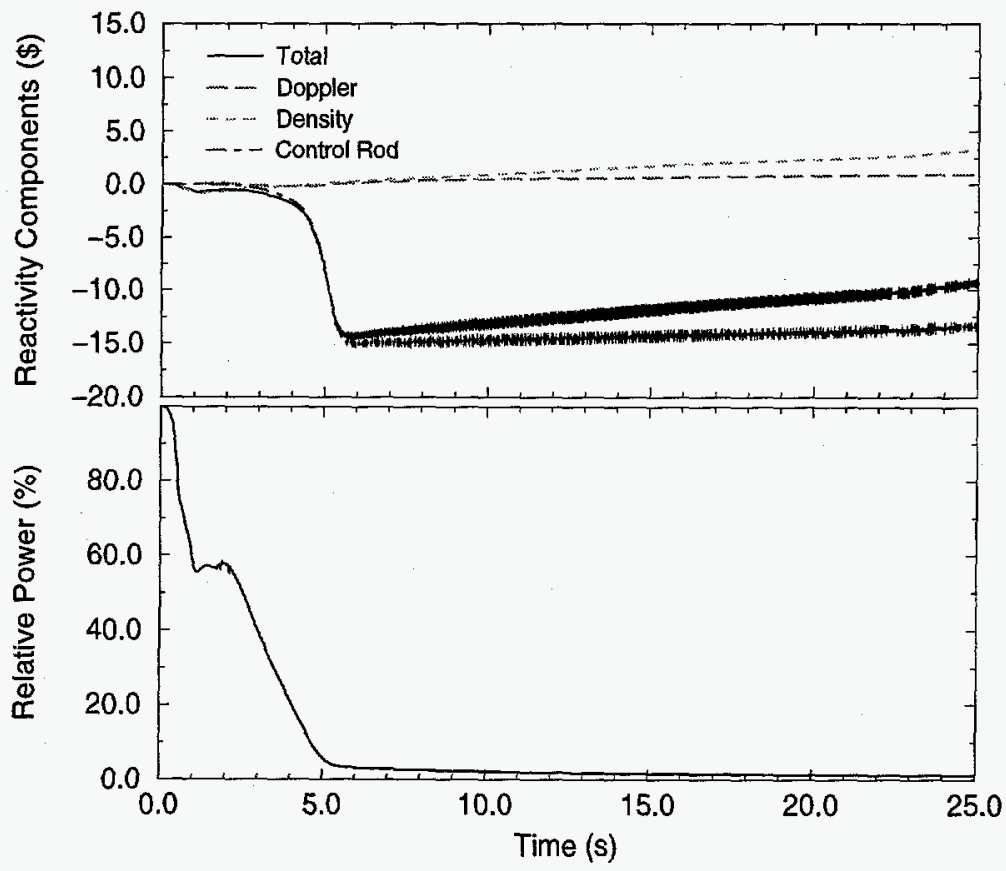

Fig. 15 Transient Summary for Westinghouse 4-Loop / Typical PWR Model 


\section{SUMMARY AND CONCLUSIONS}

This paper has presented a generalized interface module for the coupling of any thermal-hydraulics code with any spatial kinetics code. The design of the General Interface is basic enough to accommodate both internal (i.e. the systems code obtains the core thermal-hydraulic solution) and external (i.e. the spatial kinetics code obtains the core thermal-hydraulic solution) coupling strategies. With regard to the temporal coupling, the design is inherently explicit due to the modular nature of the coupling. However, the General Interface is designed with a highly adaptive structure which provides a useful framework for investigating more implicit coupling schemes (e.g. predictor-corrector methods).

The successful application of this General Interface to the coupling of both RELAP5/PARCS and TRAC-M/PARCS was also discussed. The assessment of RELAP5/PARCS has been performed using two rod ejection problems from the NEACRP benchmark specifications, and an OECD MSLB benchmark problem. The results of the rod ejection problems obtained with RELAP5/PARCS compared very well against the published reference solutions. For the MSLB problem, the analysis results showed that there was a return-to-power occurring with the maximum magnitude of $33.1 \%$ around 60 sec. The entire transient behavior, which involved wide variations in the thermal-hydraulic properties and significant distortion of the radial power distribution due to the presence of the stuck rod, was simulated with sufficient accuracy by the RELAP5/PARCS code system.

The assessment of TRAC-M/PARCS is only in the preliminary stages. Nonetheless, the capability of TRAC-M/PARCS to perform both a steady-state initialization involving a critical boron concentration search, and a transient calculation was demonstrated for a typical PWR model. Currently, work is underway to produce a TRAC-M/PARCS model of the second exercise of the OECD MSLB problem which is consistent with the RELAP5/PARCS model, and thus provide a cross-assessment of both coupled codes.

\section{ACKNOWLEDGEMENTS}

This work was funded by the U.S. Nuclear Regulatory Commission, and the authors wish to acknowledge the support of Dr. Farouk Eltawila and members of the NRC staff.

\section{REFERENCES}

Beam, T, Ivanov, K, and Baratta, A, 1998. Preliminary Report on First Phase of OECD PWR MSLB Benchmark. 2nd Benchmark Workshop, Madrid, Spain, May 22-23.

Finnemann, H. NEACRP-3: LWR Core Transient Benchmark, NEACRP-L-335 (Revision 1), Nuclear Energy Agency, January 1992. 
Geist, A., Beguelin, A., Dongarra, J., Jiang, W., Manchek, R., Sunderam, V., 1994. PVM: Parallel Virtual Machine, MIT Press, Massachusetts.

Gose, G., Downar, T., Ott, K., 1998. Analysis of the Reactivity During a PWR Main Steam Line Break Transient. Nucl. Tech. 124, p.284.

Ivanov, K., Beam, T., Baratta, A., Irani, A., Trikouros, N. PWR MSLB Benchmark - Final Specifications, NEA/NSC/DOC(97)15, Nuclear Energy Agency, October 1997.

Joo, H., Barber, D., Jiang, G., Downar, T. PARCS: A Multi-Dimensional Two-Group Reactor Kinetics Code Based on the Nonlinear Analytic Nodal Method, PU/NE-98-26, Purdue University, September 1998.

Knight, M.P., Bryce, P., 1997. Derivation of a Refined Panther Solution to the NEACRP PWR Rod Ejection Transients. Proc. Intl. Conf. Math. Comp., pp. 302-313, Saratoga NY, Oct. 5-9. 